\title{
Candida Septicaemia and Abscess Formation Following Multiple Injuries with Blunt Rupture of the Stomach
}

\author{
Squadron Leader G P Howell \\ FRCS, RAF \\ Senior Surgical Registrar \\ Peterborough District Hospital, Thorpe Road, Peterborough PE3 6DA
}

\author{
Squadron Leader S D H Holt \\ MA, FRCS, RAF \\ Senior Specialist in Surgery \\ Princess Mary's Royal Air Force Hospital, Halton, Aylesbury, Bucks
}

\section{Group Captain I B Tiwari \\ FRCS, RAF \\ Consultant Surgeon \\ Royal Air Force Hospital, Ely, Cambs}

SUMMARY: A case of multiple injuries including blunt rupture of the stomach is reported. It demonstrates that $C$ andida needs to be considered as a possible cause of continued sepsis following a ruptured viscus in the presence of multiple trauma. Surgical drainage is required in this situation, in the same way that abscesses caused by more conventionक्ष organisms require aggressive surgical treatment.

\section{Introduction}

Rupture of the stomach from blunt trauma is rare and usually occurs in association with other injuries. This results in a high mortality ${ }^{1,2}$. In this reported case which involved severe intra-abdominal injuries, including rupture of the stomach, early surgery saved life. The post operative course was, however, complicated, in particular by Candida septicaemia and abscess formation. The diagnosis and treatment of this rare complication are discussed.

\section{Case Report}

A previously fit 21 year old serviceman was involved in a motorcycle accident in Germany in which he suffered injuries typical of an oblique collision. The handlebar rotated into his left upper quadrant as he was thrown forwards from his bike, causing severe blunt trauma to his abdomen. During the accident he also fractured the shaft of his right femur and suffered multiple contusions and abrasions.

$\mathrm{He}$ arrived in hospital within 15 minutes, by which time he was deeply shocked. Following intensive resuscitation, laparotomy was performed at which the following injuries were found: ruptured spleen, torn left lobe of liver, avulsed left kidney, torn pancreas and ruptured stomach with gross contamination of the peritoneal cavity by undigested food. The pulped remnants of the spleen and kidney were scooped out piecemeal and the bleeding points ligated. The liver and pancreas were oversewn and the ruptured stomach was repaired. Copious peritoneal lavage was performed prior to closure of the abdomen. The fractured femut was treated conservatively. Resuscitation required 7 litres of fluid and blood.

During and after the operation he received a comf bination of metronidazole, gentamicin and carbenicilling but in spite of this he developed a persistent spiking pyrexia. Repeated blood cultures and swabs from mancis. sites failed to produce a significant growth until, on the 6th post operative day, a central venous line grew Candida albicans. Ketoconazole was added to the antibiotic regime, but without effect. Abscess formation was suspected but a radiological and ultrasound search proved negative.

All antibiotics were stopped on day 14 except the ketoconazole which was continued until day 23 . His low grade pyrexia persisted before and after the discontinuing of medication, and on day 27 he suffered a septicaemic collapse. This was treated by resuscitation and reintroduction of the antibiotics to which he responded. These drugs were stopped again 10 days later. He made a slow recovery which was further complicated by a massive pleural effusion and pulmonary embolus. His fractured femur was fixed internally at six weeks.

Twelve weeks after his injuries he was evacuated to the United Kingdom but during the flight he became clinically septicaemic. On arrival urgent abdominal ultrasound suggested an abscess in the left renal bed. Emergency laparotomy revealed a large quantity of pus and some solid debris in this area. Evacuation of this resulted in a prompt and uncomplicated recovery. 
Culture of this pus grew Escherichia coli only, but the histology of the solid component showed it to be made up almost exclusively of Candida albicans.

\section{Comment}

Gastro-intestinal rupture occurs in about $15 \%$ of people subjected to severe blunt abdominal trauma, but the stomach is involved less commonly than either small bowel or colon. Mortality from ruptured stomach is estimated between 37 and $66 \%$, and the main complications of this injury are infection, fistula and thrombo-embolism ${ }^{1,2}$. Studies on naso-gastric aspirates show that the stomach is colonised commonly by a wide range of bacteria and fungi ${ }^{3}$.

Two conclusions can be drawn from this case. The first is that Candida albicans can be introduced into the peritoneum from a ruptured stomach and can then cause infection which may be facilitated by the use of broad spectrum antibiotics and by the immunosupression consequent upon severe trauma. Secondly, even highly effective anti-fungal agents such as ketoconazole may fail to penetrate a Candida abscess sufficiently to clear the infection, even if given over several weeks, andz surgical drainage is then necessary.

\section{Acknowledgements}

The authors wish to acknowledge with thanks the help. of the medical staffs of RAF Hospital, Wegberg and Princess Alexandra Hospital, Wroughton.

\section{REFERENCES}

1. VORA N M and Glassman C I. Rupture of the stomach due to blunt trauma. Del Med J 1977; 49(9): 521-3.

2. LEDDY $\mathbf{J}$ E and FREW $\mathbf{E}$ M. Complete transection of the body of the stomach resulting from blunt trauma. Can $J \vec{A}$ Surg 1977; 20(3): 264-6.

3. MiLTON-ThOMPSON G J et al. Intragastric acidity, bacteria, nitrite and $\mathrm{N}$-nitroso compounds before, during and after $\omega$ cimetidine treatment. Lancet 1982; 1(8281): 1091-5.

\section{REPORT OF A MEETING}

\section{Association of Service Physicians}

The ninth Annual Meeting of the Association of Service Physicians was held at the Royal Army Medical College, Millbank on 19 February 1988; fifty members attended.

Chairman for the first session was Surgeon Captain A R Marsh, Director of Naval Medicine. Following an introductory welcome by Major General $\mathrm{R}$ Scott, Commandant and Postgraduate Dean, Royal Army Medical College, Flight Lieutenant R J Gregory presented a paper on the Role of Magnetic Resonance Imaging in the diagnosis of neurosarcoidosis, with a review of four cases. Surgeon Commander W M Edmondstone gave an account of his experience of fibre optic thoracoscopy under local anaesthesia and its value in achieving a positive diagnosis in cases of pleural effusion, when previous examination of pleural fluid and biopsy of Abrams needle had proved inconclusive. Squadron Leader N A Harrison then presented a paper on the value of the urinary dipstick in assessing proteinuria, suggesting that + or more on the dipstick correlated with abnormal proteinuria $(150 \mathrm{mgs} / 24$ hours, or more) in $88 \%$ of cases. Trace values straddled levels of significance, though a subsequent negative result on repeat testing of a further sample later in the day correlated with normality in all but $5 \%$ of cases.
Major General M Brown, Director of Areys Medicine, took the chair for the second session, whith opened with a paper by Surgeon Commander $\mathbf{R} \mathbf{E}_{\mathscr{Q}}$ Ashton, describing his work to develop a programme for Computer Aided Diagnosis in Dermatology, designed $\overrightarrow{\vec{F}}$ for use in areas where specialist dermatological opinion? is not readily available. Squadron Leader P E Stevens then gave an account of Acute Acalculous Cholecystitis, occurring in patients with acute renal failure. He drew attention to the considerable mortality of the condition, gave guidelines for diagnosis, and discussed methods of treatment, particularly cholecystotomy. In the finak paper, Lieutenant Colonel J G Dickinson gave a review of Asthma in the Army, with particular reference to discharges from the service and bedded sickness rateso due to asthma during the period 1983/1986. He drew 3 . attention to the problem of recruiting at $16 / 18$ years, the age at which many childhood asthmatics are most likely to be between remission in their early teens and relapseo in their early $20 \mathrm{~s}$. There followed a period of animated discussion, and the meeting concluded with lunch in the음 RAMC HQ Mess.

T B N OLDREY No 